
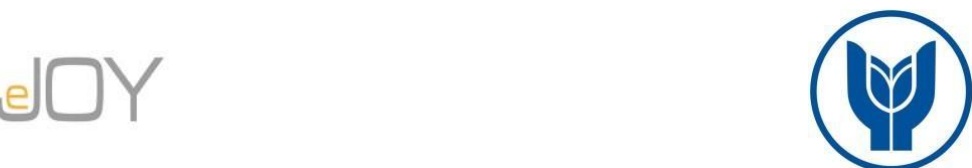

Sürücü, L., Yık1lmaz, İ. / Journal of Yasar University, 2021, 16/62, 739-753

\title{
Resonant Liderlik Ölçeğinin Türkçeye Uyarlanması: Geçerlik ve Güvenirlik Çalışması
}

\section{Adaptation of Resonant Leadership Scale into Turkish: The Validity and Reliability Study}

\author{
Lütfi SÜRÜCÜ, Avrupa Liderlik Üniversitesi, KKTC, lutfi.surucu@elu.edu.tr \\ Orcid No: 0000-0002-6286-4184 \\ İbrahim YIKILMAZ, Kocaeli Üniversitesi, Türkiye, ibrahimyklmz@gmail.com \\ Orcid No: 0000-0002-1051-0886
}

\begin{abstract}
Öz: Araştırmanın amacı Estabrooks, Squires, Cummings, Birdsell ve Norton (2009) tarafindan “Alberta Bağlam Aracının” bir alt ölçeği olarak geliştirilen resonant liderlik ölçeğinin Türkçeye uyarlaması yapılarak Türkçe yazınına kazandırılmasıdır. Araştırma amaçları doğrultusunda Kocaeli ilinde görev yapan kamu çalışanlarına anket uygulaması yapılmıştır $(N=283)$. Veriler AMOS-18 ve SPSS-24 yazılımları kullanılarak analiz edilmiştir. Uyarlama çalışması yapılan ölçeğin geçerliğinin tespitine yönelik olarak; dilsel geçerlik, benzeşim geçerliği ve yapı geçerliği test edilmiştir. Güvenirliğinin tespitine yönelik olarak da Cronbach alfa iç tutarlılık katsayısı ve bileşik güvenilirlik değeri hesaplanmış, son olarak test- tekrar test yapılmıştır. Analizler sonucunda elde edilen bulgular, uyarlama ve çeviri çalışması yapılan resonant liderlik ölçeğin geçerli ve güvenilir bir ölçme aracı olduğunu göstermektedir. Araştırmanın resonant liderliğe yönelik anlayışımızı zenginleştirmenin yanı sıra ileride yapılacak olan çalışmalara kaynak teşkil edecĕgi değerlendirilmektedir.
\end{abstract}

Anahtar Sözcükler: Resonant Liderlik Ölçeği, Güvenilirlik, Geçerlik, Uyarlama

JEL Sinıflandırmast: C10, D23, L31, M12

\begin{abstract}
The aim of the study is to adapt the resonant leadership scale developed as a subscale of the "Alberta Context Tool" by Estabrooks, Squires, Cummings, Birdsell, and Norton (2009) to Turkish literature. In line with the research purposes, a questionnaire was applied to public employees working in Kocaeli Province $(N=283)$. The data were analyzed by using AMOS-18 and SPSS-24 software. To determine the validity of the scale for which the adaptation study was made; translation validity, convergent validity, and construct validity were tested. To determine the reliability, Cronbach's alpha internal consistency coefficient and composite reliability value were calculated, and finally, a test-retest was performed. The findings obtained as a result of the analysis show that the resonant leadership scale, which has been adapted and translated, is a valid and reliable measurement tool. It is considered that the research will enrich our understanding of resonant leadership as well as constitute a source for future studies.
\end{abstract}

Keywords: Resonant Leadership Scale, Reliability, Validity, Adaptation

JEL Classification: C10, D23, L31, M12

\section{Giriş}

Yaşanan teknolojik gelişmeler ve küreselleşme ile beraber, örgütlerin insan sermayesindeki çeşitlilik artmıştır. Günümüzün liderleri giderek artan çeşitliliği yönetmek, örgüt içerisinde huzur ortamını sağlamak ve sağlanan bu huzur ortamını sürdürmekten sorumludur. Liderin örgüt içindeki çoklu görev ve sorumluluklarının yanı sıra çalışanların çeşitliliğinden kaynaklanan kişilerarası ilişkileri yönetmekteki yaşanan zorluklar, liderin rol karmaşıklığını 
daha da artırır. Yaşanan bu gelişmeler doğrultusunda Turk ve Wolfe (2019: 150), çeşitlilik yönetimi için örgütlerin duygusal zekâya sahip ahenk yaratan liderlere (resonant) ihtiyacı olduğunu belirtmektedir.

Resonant liderler; duygusal, sosyal ve kültürel zekâlarını kullanarak çalışanlar için en iyisini yapma çabasındadır (McKee ve Massimilian, 2006: 212). Başkalarıyla ilişkileri güçlüdür ve kurdukları ilişki güvene dayanır. Duyguların bulaşıcı doğasını bilerek, çevrelerinde umut ve iyimserlik ortamı yaratmak için duygularını yönetirler (Hassan ve Qureshi, 2019: 239). Çalışanlarıyla ilişkilerinde empati gösterir ve entelektüel kaynaklarını kullanarak örgüt için olumlu sonuçlar üretirler. Yapılan araştırmalar, resonant liderliğin örgütsel bağl1lık, iş tatmini (Wagner, Warren, Cummings, Smith ve Olson, 2013: 120) ve psikolojik güçlendirme (Kushwaha, 2019: 4) ile ilişkili olduğunu göstermektedir. Daha ileri yapılan araştırmalarda ise resonant liderliğin; örgütsel adalet algısını ve çalışma ortamının kalitesini artırdığı (Squires, Tourangeau, Laschinger ve Doran, 2010: 921) ayrıca pozitif örgüt kültürünün oluşmasına önemli katkılarının olduğu tespit edilmiştir (Laschinger, Wong, Cummings ve Grau, 2014: 11).

Resonant lider görünür ve erişilebilirdir. Personelin endişelerini dinler, gelişimlerine önem verir, çatışmaları yönetir ve çalışanlarını yenilikçi kararlar alma konusunda güçlendirir (Cummings, 2004: 77). Bu yönleriyle resonant lider, dönüştürücü liderlik tarzıyla benzerlik gösterir. Her iki liderlik tarzı hem bireysel olarak hem de daha geniş sosyal ortamlarda kendi duygularını ve başkalarıyla olan ilişkilerini nasıl yöneteceklerine odaklanmaktadır (Estabrooks, Squires, Cummings, Birdsell ve Norton, 2009: 2). Ayrıca dönüştürücü ve resonant liderler ikili ilişkilere önem vererek çalışan katılımını teşvik eden pozitif çalışma ortamları yaratırlar (Laschinger vd., 2014: 8). Resonant lider tüm bu olumlu faaliyetleri yüksek duygusal zekâsıyla yapar. Bu yönüyle dönüştürücü liderlik teorisinden ayrılmaktadır (Goleman, Boyatzis ve McKee, 2002).

Duygusal zekâya dayanan resonant lider, kendi duyguları ve başkalarının duygularını yönetme yeteneğine sahiptir. Duygusal zekâsını çalışanlarına destek ve şefkat göstermek için kullanır. Çalışanları ile uyum içerisinde çalışır ve güven temelinde ilişkiler kurarak iyimserliğin hâkim olduğu bir çalışma ortamı yaratır (Squires vd., 2010: 916). Resonant lider altında çalışanlar, çalışma ortamlarında kendilerine değer verildiğini, tanındığını, takdir edildiğini ve desteklendiklerini hissederler (Cummings vd., 2008: 509). Çalışanlarında olumlu duygular yaratması yönüyle resonant liderliğe, ilişkisel bir liderlik tarzı da denilebilir (Bawafaa, 2014: 20). 
Liderlik literatüründe yeni bir kavram olan resonant liderliğin ampirik olarak ölçülebilmesi için Estabrooks vd. (2009: 2-10) tarafindan ölçek geliştirilmiştir. Literatür, geliştirilen ölçeklerin araştırmanın yapıldı̆̆ verebileceğine vurgu yapmaktadır (Sürücü ve Maslakçı, 2020: 2717). Mevcut kültürel farklılıklar, araştırma sonuçlarında tutarsızlığa sebep olurken araştırmanın geçerliliğini de tehdit edebilmektedir (Gürbüz ve Şahin, 2016: 152). Bu nedenle, farklı kültürde geliştirilmiş ölçeklerin araştırmanın yapıldığı kültüre uyarlanması, geçerlik ve güvenirliğinin test edilmiş olması önemlidir. Bu maksatla araştırmada, geliştirilen resonant liderlik ölçeğinin Türkçeye uyarlama ve çeviri çalışması yapılarak ölçeğin Türkçe yazına kazandırılması hedeflenmiştir. $\mathrm{Bu}$ maksatla araştırma üç bölümden oluşturulmuştur. Birinci bölümde resonant liderliğe yönelik literatüre yer verilmiş, ikinci bölümde ölçeğin orijinal formundan Türkçeye uyarlama, geçerlik ve güvenirlik analizleri yapılmıştır. Son bölümde ise elde edilen bulgular doğrultusunda sonuç bölümü oluşturulmuştur. Yapılan bu araştırmanın resonant liderlik konusundaki anlayışımızı geliştireceği ve ileride yapılacak araştırmalara kaynak teşkil edeceği değerlendirilmektedir.

\section{Resonant Liderlik}

Çalışanların ruh halleri ve duyguları sürekli değişim göstermektedir. Bu nedenle çalışanlarını örgütün başarısı için yönlendirmek ve yönetmek liderin, karşılaştığı önemli zorluklardan biri olarak kabul edilir. Hassan ve Qureshi (2019: 238) duygusal zekâsı yüksek liderlerin bu zorlukla başa çıkabildiğini iddia etmektedir. Literatür, duygusal zekânın liderin etkinliğinde önemli katkılarının olduğu fikrini desteklemektedir (Cummings, 2004: 77; Freshman ve Rubino 2002: 4; Goleman vd., 2002; Pirola-Merlo, Härtel, Mann ve Hirst, 2002: 577).

Resonant liderler yüksek düzeyde duygusal zekâ ile donatılmıştır (McKee ve Massimilian, 2006: 214). Resonant liderliğin temel ilkeleri, duygusal zekâ ve esneklik modellerinin birçok yönüyle uyumludur. Nitekim araştırmacılar resonant liderliği, duygusal zekâ ve dayanıklılık temelinde kavramsallaştırmaktadır (Estabrooks vd., 2009: 2). Örneğin Cummings (2006: 323) resonant liderliği, dört duygusal zekâ yetkinliğini (yani öz farkındalık, özyönetim, sosyal farkındalık ve ilişki yönetimi) dâhil ederek kavramsallaştırırken, Reivich ve Shatté (2002) öz farkındalık, başkalarının farkındalığı, umut, iyimserlik, şefkat ve empati becerilerinin resonant liderliğin temeli oluşturduğunu belirtmektedir. Turk ve Wolfe (2019: 150) ise duygusal farkındalık, esneklik, doğru düşünme, iyimserlik ve empatiyi resonant liderliğin önemli unsurları olarak tanımlanmaktadır. 
Yukarıda özetlenen çeşitli becerilere sahip resonant lider, başkalarının duygularına uyum sağlar ve çevrelerindeki insanların kendi değerlerini ve duygularını içtenlikle ifade ederek onları duygusal olarak olumlu bir yöne sevk edebilir (Goleman, Boyatzıs, Mckee ve Finkelstein, 2017). Bu yönüyle resonant liderler, kendisinin ve başkalarının duygularını başarıya götürebilecek şekilde yönetebilen bireylerdir (Goleman vd., 2002; Turk ve Wolfe, 2019: 151).

Resonant lider dört liderlik tarzının birleşmesiyle oluşmaktadır (Cummings, 2004: 75). Bunlar; başkalarını geliştirmeye odaklanan koçluk liderliği, bilgiyi ve nüfuzu paylaşarak insanları paylaşılan hayallere doğru yönlendiren vizyoner liderlik, çalışanları ile güçlü ilişkiler kuran örgütsel bağlılık odaklı liderlik ve fikir birliği oluşturan, ekip çalışmasını ve işbirliğini teşvik eden demokratik liderlik tarzlarıdır (Cummings, 2004: 76).

Resonant lider, önderlik ettikleri kişiler arasında ahenk oluşturmak için duygusal zekâsını kullanır ve kendi duygusal zekâsının içe dönük gelişimiyle ilgilenir (McKee, Boyatzis, Johnston ve Johnston, 2008: 151). Resonant liderin yüksek duygusal zekâsı örgüt için elverişli bir çalışma ortamı yaratılmasını sağlar. Oluşturulan ortam; verimlilik, yaratıcılık, birlik, amaç ve sonuçları destekleyen güçlü bir kolektif enerji yaratır (Turk ve Wolfe, 2019: 150). Son yirmi yılda yapılan araştırmalar, duygusal zekâsı yüksek olan bir liderin, çalışanlarıyla güvene dayalı ilişkiler kurarak canlı bir çalışma ortamı yarattığını ve böylelikle örgütün başarısını artırdığını belgelemektedir (Klein, 2009; Ramírez Molina, del Valle Marcano, Ramírez Molina, Lay Raby ve Herrera Tapias, 2019).

Resonant lider, pozitiflik ve heyecan yaratmak için güçlü bir arzuya da sahiptir (Goleman, 1998: 37). Çalışanlarına ilham vermek için kişisel tutku, özgünlük ve coşkusunu kullanır ve çalışanların ihtiyaçlarını anlamak için empati yapar. Temel amaçları çalışanlarıyla güven ortamı oluşturmak ve verimli bir işbirliği sağlamaktır. Güvene dayalı ilişkiler kurulmasıyla birlikte tüm çalışanlarının gelecek hakkında iyimser olduğu, kişisel ve profesyonel olumsuzluklarla sebat ettiği bir ortam yaratılır (McKee vd., 2008: 154). Oluşturulan bu sebat ortamıyla beraber çalışanların motivasyonu, örgütsel bağlılı̆̆ı ve üretkenliğini artacaktır.

\section{Metot}

\subsection{Prosedür ve Örneklem}

Araştırmanın evrenini Kocaeli'nde görev yapan kamu kurum çalışanları oluşturmaktadır. Araştırma yapılmadan önce ölçeği geliştiren yazarlardan biri olan Greta G. Cummings (gretac@ualberta.ca) ile irtibata geçilmiş ve geliştirilen resonant liderlik ölçeğinin Türkçeye uyarlama ve çeviri çalışmasının yapılabilmesi için müsaade istenmiştir. Müsaadenin 
alınmasına müteakip araştırma için Kocaeli Üniversitesi Sosyal ve Beşeri Bilimler Etik Kurulu'ndan etik kurul izni alınmıştır (Etik kurul Karar Nu: 6). Anket uygulaması aşamasında Kocaeli'ndeki kamu kuruluşlarının amirleri ile görüşülmüş ve araştırma hakkında bilgilendirilmiştir. Araştırmanın yapılmasına müsaade eden kurum amirlerinin çalışanlarına anket uygulaması yapılmıştır. Anket uygulaması bizzat araştırmacılar tarafından yüz yüze ve yerinde yapılmıştır. Anketin uygulama aşamasında katılımcılara anket hakkında bilgi verilmiş, verilerin üçüncü şahıslar ile paylaşılmayacağı ve isimlerinin gizli tutulacağı konusunda taahhüdünde bulunulmuştur. Araştırmaya katılım göstermek isteyen çalışanlara anket uygulaması yapılmıştır.

Araştırmanın yapılabilmesi için 350 anket hazırlanmıştır. Hazırlanan anketler araştırmacılar tarafından katılımcılara uygulanmış ve 307 anket verisi elde edilmiştir. Araştırma iki hafta sürdürülmüştür. Elde edilen anketler aykırı değerlere göre incelenmiş ve 24 anket verisi araştırmadan çıkarılmıştır. Araştırma 283 geçerli anket verisi ile tamamlanmıştır.

Katılımcıların 164'ü erkek, 119'u kadındır. Bu katılımcıların 189'u evli, 93'ü bekârdır. 4 katılımcı doktora, 32 katılımcı yüksek lisans, 226 katılımcı lisans ve 21 katılımcı ön lisans ve altı eğitime sahiptir. Katılımcıların 32'si yönetici, 251'i çalışan konumundadır.

\subsection{Resonant Liderlik Ölçeği}

Resonant liderlik ölçeği Estabrooks ve arkadaşları tarafından 2009 yılında "Alberta Bağlam Aracının geliştirilmesi ve değerlendirilmesi” başlıklı çalışmasında Alberta Bağlam Aracının bir alt ölçeği olarak geliştirilmiştir. Araştırmacılar resonant liderliği tek boyutlu olarak 10 ifade ile ölçmektedir. Ayrıca aynı ölçekte resonant liderliğin 6 ifadeli kısa versiyonu da (1, 3, 5, 6, 7 ve 8. ifadeler) bulunmaktadır. Ters kodlu bir ifadenin bulunmadığı ölçekteki ifadeler 5'li likert tipinde hazırlanmıştır. Ankete verilen yanıtlardan; 1= Hiç Katılmıyorum, 2= Katılmiyorum, 3= Kararsızım, 4= Katıliyorum ve 5= Tamamen Katıliyorum'u ifade eder. Ölçekten elde edilen puan 10 ile 50 arasında değişebilir. Ölçekten alınan puan ne kadar yüksekse, çalışanların en yakın amirlerinin bu tür liderlik davranışlarını daha fazla sergilediğini gösterir. Estabrooks vd. (2009: 7) tarafından yapılan ölçek geliştirme çalışmasında, ölçüm aracı güçlü bir iç tutarlılık $(\alpha=0.95)$ ve geçerlilik göstermiştir.

\section{3. Çeviri ve Ön Test}

Resonant liderlik ölçeğinin orijinal formu İngilizcedir. İngilizceden Tükçeye çeviri işleminde Brislin, LonnerWalter ve Thorndike (1973) tarafından önerilen 5 aşamalı çeviri tekniği kullanılmıştır. Bu aşamalar; ilk çevirinin yapılması, ilk çevirinin değerlendirilmesi, ölçeğin 
orijinal formuna geri çevirme, geri çevirinin değerlendirilmesi ve son aşama olan uzman görüşünün alınmasıdır. Bu kapsamda öncelikle doktora eğitimine sahip iki akademisyen tarafından ölçeğin orijinal formu olan İngilizceden Türkçeye çevrilmiştir. Çevirisi yapılan ölçek farklı iki akademisyen tarafindan ifadelerin anlaş1lırlığı ve kültürel uygunluğu değerlendirilmiştir. Elde edilen Türkçe ölçek İngiliz Dil ve Edebiyatı Bölümü’nde görev yapan iki akademisyen tarafından tekrar İngilizceye çevrilmiştir. Bir uzman tarafından da geri çevrilen ölçek ile ölçeğin orijinal formu değerlendirilmiştir. Dilsel eşitlik sağlandığının anlaşılmasından sonra çeviri işlemi tamamlanmış ve ölçeğin kullanılmasına karar verilmiştir. Çeviri çalışması yapılan ölçek önce 42 kişilik örnek gruba uygulanarak anlaşılmayan ya da tereddüt yaşanan ifadelerin varlığı kontrol edilmiştir. Ölçek içerisinde yer alan tüm ifadelerin katılımcılar tarafından doğru anlaşıldığının tespit edilmesinden sonra çeviri işlemi sonlandırılmıştır. Resonant liderlik ölçeğinde yer alan ifadelerin çevirisi Tablo 1'de sunulmuştur.

Tablo 1. Resonant Liderlik Ölçeği

\begin{tabular}{|c|c|}
\hline $\begin{array}{l}\text { Ifade } \\
\mathrm{Nu}\end{array}$ & Ifadeler \\
\hline $\begin{array}{c}1 \\
* *\end{array}$ & Amirim, stresli durumları sakin bir şekilde ele alır. \\
\hline 2 & $\begin{array}{l}\text { Amirim, aktif bir şekilde dinler, kabul eder ve ardından istek ve endişeleri } \\
\text { yanıtlar. }\end{array}$ \\
\hline $\begin{array}{c}3 \\
* * \\
\end{array}$ & $\begin{array}{l}\text { Amirim, aktif olarak başkalarının performansına mentorluk ve koçluk } \\
\text { yapar. }\end{array}$ \\
\hline 4 & Amirim, hedeflere ve sonuçlara ulaşmak için ekip çalışmasını destekler. \\
\hline $\begin{array}{c}5 \\
* *\end{array}$ & Amirim, ortaya çıkan çatışmaları etkin bir şekilde çözer. \\
\hline $\begin{array}{c}6 \\
* *\end{array}$ & $\begin{array}{l}\text { Amirim, diğerlerini paylaşılan bir vizyon doğrultusunda çalışmaya davet } \\
\text { eder. }\end{array}$ \\
\hline $\begin{array}{c}7 \\
* *\end{array}$ & Amirim, başarısızlıklardan ziyade başarıya odaklanır. \\
\hline $\begin{array}{c}8 \\
* *\end{array}$ & $\begin{array}{l}\text { Amirim, diğerlerinin işlerinde önemli kararlar almalarında özgür } \\
\text { olmalarına izin verir. }\end{array}$ \\
\hline 9 & Amirim, sonuçları açısından işitmesi zor olsa da geribildirim bekler. \\
\hline 10 & Amirim, kişisel bedeli olsa bile değerlerine bağlı hareket eder. \\
\hline
\end{tabular}




\subsection{Istatistiksel Analiz}

Analizler, AMOS-18 ve SPSS 24.0 istatistik yazılımı kullanılarak yapılmıştır. Örneklem büyüklüğünün yeterliliğini değerlendirmek için Bartlett's testi ve Kaiser-Meyer-Olkin (KMO) testleri yapılmıştır. Ölçeğin güvenirliği tespitine yönelik olarak Cronbach alfa iç tutarlılık katsayısı (Cronbach, 1951), bileşik güvenilirlik değeri (Fornell ve Larcker, 1981) hesaplanmış ve test- tekrar test uygulanmıştır. Geçerliğinin tespitine yönelik olarak; dilsel geçerlik, benzeşim geçerliliği ve yapı geçerliği test edilmiştir.

\section{Bulgular}

\subsection{Geçerlik Çalışması}

Geçerlik, ölçüm aracının amaçlanan kullanımına yönelik olarak uygun verilerin elde edilmesi olarak tanımlar (Whiston, 2012). Geçerlilik, ölçüm aracının ölçmeyi istediği davranışı ya da niteliği gerçekten ölçüp ölçmediği ile ilgidir ve ölçüm aracının işlevini ne kadar iyi yerine getirdiğinin bir ölçüsüdür (Anastasi ve Urbina, 1997, Sürücü ve Maslakçı, 2020: 2695). Çeviri ve uyarlama çalışması yapılan resonant liderlik ölçeğinin geçerliliğinin tespitine yönelik olarak öncelikle dilsel geçerlilik kontrol edilmiştir.

Dilsel geçerliğin tespitine yönelik olarak Hambleton ve Bollwark (1991) tarafından önerilen yöntem kullanılmıştır. Buna göre, ölçeğin orijinal formu ve çevirisi yapılan dildeki formu aynı örneklem grubuna iki hafta ara ile uygulanmalıdır. Bu kapsamda İngilizce diline hâkim 47 kişilik örneklem grubuna önce Türkçe formu, iki hafta sonrasında ise ölçeğin orijinal (İngilizce) formu uygulanmıştır. Katılımcıların her iki forma verdikleri yanıtlar arasındaki ilişki Pearson momentler çarpım korelasyon katsayısı ile ölçülmüştür. İki form arasında 10 ifadeli ölçeğin korelasyonu $r=0,901 \quad(\mathrm{p}<0,05), 6$ ifadeden oluşan kısa versiyonunun korelasyonu ise $r=0,884(\mathrm{p}<0,05)$ olarak ölçülmüştür. Bu değerler çeviri ve uyarlama çalışması yapılan ölçeğin dilsel geçerliliğinin olduğunu göstermektedir (Hambleton ve Bollwark, 1991).

Benzeşim geçerliği değişkenlere ilişkin ifadelerin birbirleriyle ve oluşturmuş oldukları faktörle ilişkili olmalarını ifade eder ve belirli bir yapıyı ölçmek için tasarlanmış ölçüm aracının, gerçekten de bu yapıyı doğru ölçtügü anlamına gelir (Sürücü ve Maslakçı, 2020: 2701). Benzeşim geçerliliğin sağlanabilmesi için ortalama açıklanan varyans (AVE) değerlerinin birleşik güvenirlik değerinden küçük olması ve her bir AVE değerinin ise 0,5 değerinden büyük olması gerekmektedir (Sürücü ve Maslakçı, 2020: 2701). Benzeşim geçerliğinin tespit edilmesinde diğer bir yöntem ise AVE’nin karekök değerinin, birleşik güvenirlik, Cronbach alfa $(\alpha)$ ve AVE değerlerinden küçük olması temeline dayanır. $\mathrm{Bu}$ 
durumda da ölçeğin benzeşim geçerliğini sağladığı belirtilir (Sürücü ve Maslakçı, 2020: 2702). Uyarlama ve çeviri çalışması yapılan ölçeğin benzeşim geçerliğinin tespit edilmesine yönelik olarak; AVE değeri 0,507, Cronbach alfa değeri 0,909 ve birleşik güvenirlik değerleri 0,912 ölçülmüştür. Kısa versiyonun; AVE değeri 0,526, Cronbach alfa değeri 0,864 ve birleşik güvenirlik değerleri 0,867 'dir. Ortalama açıklanan varyans (AVE) değerlerinin birleşik güvenirlik değerinden küçük olması ve AVE değerinin 0,5 değerinden büyük olması çeviri ve uyarlama çalışması yapılan ölçeğin benzeşim geçerliğin olduğunu göstermektedir.

Yapı Geçerliği: Yapı geçerliği, ölçüm aracının ölçmesi gereken kuramsal bir yapı1 (kavram, davranış, fikir veya niteliği) ölçme derecesi ile ilgilidir (Sürücü ve Maslakçı, 2020: 2700). Diğer bir ifade ile ölçülmek istenen davranış ya da niteliğe sahip olan ve olmayan katılımcıları ayırt edebilme yeteneğidir (Sürücü ve Maslakçı, 2020: 2700). Uyarlama ve çevirisi yapılan resonant liderlik ölçeğinin yapı geçerliliği "Keşfedici Faktör Analizi (KFA)" ve "Doğrulayııı Faktör Analizi (DFA)" yapılarak tespit edilmiştir. Elde edilen sonuçlar Tablo 2'de sunulmuştur.

Tablo 2. Resonant Liderlik (10 ifade) Ölçeğinin Faktör Analizi Sonuçları

\begin{tabular}{|c|c|c|c|c|c|}
\hline \multirow{2}{*}{$\begin{array}{l}\text { Ifade } \\
\mathrm{Nu}\end{array}$} & \multirow{2}{*}{ Ölçekte Yer Alan İfadeler } & \multirow{2}{*}{ Ort. } & \multirow{2}{*}{$S D$} & \multicolumn{2}{|c|}{ Faktör Yükleri } \\
\hline & & & & KFA & $D F A$ \\
\hline$R L 1$ & Amirim, stresli durumları sakin bir şekilde ele alır. & 3,52 & 1,134 & ,663 & ,667 \\
\hline$R L 2$ & $\begin{array}{l}\text { Amirim, aktif bir şekilde dinler, kabul eder ve } \\
\text { ardından istek ve endişeleri yanıtlar. }\end{array}$ & 3,55 & 1,145 &, 819 & ,809 \\
\hline$R L 3$ & $\begin{array}{l}\text { Amirim, aktif olarak başkalarının performansına } \\
\text { mentorluk ve koçluk yapar. }\end{array}$ & 3,33 & 1,096 &, 850 &, 860 \\
\hline$R L 4$ & $\begin{array}{l}\text { Amirim, hedeflere ve sonuçlara ulaşmak için ekip } \\
\text { çalışmasını destekler. }\end{array}$ & 3,78 & 1,004 &, 807 &, 800 \\
\hline$R L 5$ & $\begin{array}{l}\text { Amirim, ortaya çıkan çatışmaları etkin bir şekilde } \\
\text { çözer. }\end{array}$ & 3,37 & 1,000 &, 787 & ,797 \\
\hline$R L 6$ & $\begin{array}{l}\text { Amirim, diğerlerini paylaşılan } \text { bir } \\
\text { doğrultusunda çalışmaya davet eder. }\end{array}$ & 3,62 & 0,972 &, 811 &, 812 \\
\hline$R L 7$ & $\begin{array}{l}\text { Amirim, başarısızlıklardan ziyade başarıya } \\
\text { odaklanır. }\end{array}$ & 3,78 & 0,864 &, 575 &, 571 \\
\hline$R L 8$ & $\begin{array}{l}\text { Amirim, diğerlerinin işlerinde önemli kararlar } \\
\text { almalarında özgür olmalarına izin verir. }\end{array}$ & 3,58 & 0,995 &, 625 &, 595 \\
\hline$R L 9$ & $\begin{array}{l}\text { Amirim, sonuçları açısından işitmesi zor olsa da } \\
\text { geribildirim bekler. }\end{array}$ & 3,88 & 0,865 &, 551 &, 504 \\
\hline$R L 10$ & $\begin{array}{l}\text { Amirim, kişisel bedeli olsa bile değerlerine bağli } \\
\text { hareket eder. }\end{array}$ & 3,40 & 0,996 & ,609 & ,605 \\
\hline & Toplam Açıklanan Varyans & \multicolumn{4}{|c|}{51,587} \\
\hline
\end{tabular}


Keşfedici faktör analizi, temel bileşenler metodu ve varimaks eksen döndürmesi tekniği kullanılarak yapılmıştır. KFA neticesinde, Kaiser-Meyer-Olkin (KMO) örneklem yeterlilik değerinin 0,923 olduğu ve örneklemin büyüklüğünün faktör analizi için yeterli olduğu tespit edilmiştir. Bartlett küresellik testinin anlamlı olması $X^{2}(45)=1552,631, p<0,001$ değişkenler arasındaki korelasyon ilişkilerinin faktör analizi için uygun olduğuna işaret etmektedir. Faktör analizinde öz değeri 1'den büyük olanların faktör oluşturulması sağlanmıştır. Bu göre 10 ifadeli resonant liderlik ölçeğinin tek faktörlü bir yapıya sahip olduğu ve toplam varyansın \%51,587'sini açıkladığı tespit edilmiştir. İfadelerin faktör yüklerinin 0,551 ve üzerindedir. Literatür faktör yüklerinin 0,50 'den büyük olmasının, ifadelerin iyi seviyede ayırt edici özelliğinin olduğunu belirtmektedir (Hair, Black, Babin ve Anderson, 2010; Tabachnick, Fidell ve Ullman, 2007; Sürücü ve Maslakçı, 2020).

Estabrooks vd. (2009) tarafından yapılan ölçek geliştirme çalışmasında, resonant liderlik ölçeğinin kısa versiyonunda 6 ifade kullanılmıştır. Bu nedenle araştırmada kısa versiyonunun da geçerliği test edilmiştir. Aynı esaslarda yapılan faktör analizi sonuçları Tablo 3'de sunulmuştur.

Tablo 3. Kısa versiyon Resonant liderlik (6 ifade) Ölçeğinin Faktör Analizi Sonuçları

\begin{tabular}{|c|l|c|c|c|c|}
\hline $\begin{array}{c}\text { Ifade } \\
N u\end{array}$ & \multicolumn{1}{|c|}{ Ölçekte Yer Alan Ifadeler } & \multirow{2}{*}{ Mean } & SD & \multicolumn{2}{|c|}{ Faktör Yükleri } \\
\cline { 5 - 7 } & \multicolumn{2}{|c|}{ KFA } & DFA \\
\hline RL1 & Amirim, stresli durumları sakin bir şekilde ele alır. & 3,52 & 1,134 &, 676 &, 676 \\
\hline RL3 & $\begin{array}{l}\text { Amirim, aktif olarak başkalarının performansına } \\
\text { mentorluk ve koçluk yapar. }\end{array}$ & 3,33 & 1,096 &, 836 &, 836 \\
\hline RL5 & $\begin{array}{l}\text { Amirim, ortaya çıkan çatışmaları etkin bir şekilde } \\
\text { çözer. }\end{array}$ & 3,37 & 1,000 &, 819 &, 819 \\
\hline RL6 & $\begin{array}{l}\text { Amirim, diğerlerini paylaşı1lan bir vizyon } \\
\text { doğrultusunda çalışmaya davet eder. }\end{array}$ & 3,62 & 0,972 &, 804 &, 804 \\
\hline RL7 & $\begin{array}{l}\text { Amirim, başarısılıklardan ziyade başarıya } \\
\text { odaklanır. }\end{array}$ & 3,78 & 0,864 &, 564 &, 564 \\
\hline RL8 & $\begin{array}{l}\text { Amirim, diğerlerinin işlerinde önemli kararlar } \\
\text { almalarında özgür olmalarına izin verir. }\end{array}$ & 3,58 & 0,995 &, 602 &, 602 \\
\hline \multicolumn{1}{|c|}{ Toplam Açılanan Varyans } & 52,578 & \\
\hline
\end{tabular}

Estabrooks vd. (2009) tarafından önerilen kısa versiyon resonant liderlik ölçeğine yönelik yapılan KFA analiz sonuçları; Kaiser-Meyer-Olkin (KMO) örneklem yeterlilik değerinin 0,881 olduğu ve Bartlett küresellik testinin anlamlı olduğunu $\left(X^{2}(15)=740,925, \mathrm{p}<0,001\right)$ göstermektedir. 6 ifadeli resonant liderlik ölçeği, öz değeri 1'den büyük tek faktörlü yap1 oluşturmaktadır. Toplam varyansın \%52,578'ini açıklayan tek faktörlü yapının faktör yükleri 
0,564 - 0,836 arasında değişmektedir. Buna göre resonant liderlik ölçeğinin kısa versiyonun da ayırt edici özelliğinin olduğunu tespit edilmiştir.

Doğrulayıcı faktör analizi (DFA), tek faktörlü resonant liderlik ölçeğinin uzun ve kısa versiyonlarının yapı geçerliliğini test etmeye yönelik olarak AMOS 18 programı yardımıyla yapılmıştır. Kovaryans matrisinin maksimum olasılık tahmini kullanılarak yapılan DFA sonuçları Tablo 3'de, analiz diyagramı ise Şekil 1 ve Şekil 2'de gösterilmiştir.

Tablo 4. Resonant Liderlik Ölçeğinin Uyum İyiliği Değerleri

\begin{tabular}{|c|c|c|c|c|c|c|c|c|}
\hline Ölçek & $\Delta X^{2}$ & $D f$ & $\chi^{2} / d f$ & $G F I$ & NFI & TLI & CFI & RMSEA \\
\hline $\begin{array}{c}\text { Uzun Versiyon } \\
\text { (10 ifade) }\end{array}$ & 67,904 & 32 & 2,122 & 0,954 & 0,957 & 0,967 & 0,977 & 0,063 \\
\hline $\begin{array}{c}\text { Kisa Versiyon } \\
\text { (6 ifade) }\end{array}$ & 17,529 & 9 & 1,948 & 0,979 & 0,977 & 0,981 & 0,988 & 0,058 \\
\hline
\end{tabular}

Tablo 4'deki değerler resonant liderlik ölçeğinin uzun ve kısa versiyonunun tek faktörlü yapıda olduğunu ve iyi uyum indekslerine sahip olduğunu göstermektedir (on ifadeli uzun versiyon; $\chi 2=67,904, \mathrm{df}=32, \chi 2 / \mathrm{df}=2,122, \mathrm{GFI}=0,954, \mathrm{NFI}=0,957, \mathrm{TLI}=$ 0,967, $\mathrm{CFI}=0,977, \mathrm{RMSEA}=0,063$, alt1 ifadeli k1sa versiyon; $\chi 2=17,529, \mathrm{df}=9, \chi^{2} / \mathrm{df}=$ 1,948, GFI $=0,979, \mathrm{NFI}=0,977, \mathrm{TLI}=0,981, \mathrm{CFI}=0,988, \mathrm{RMSEA}=0,058) . \mathrm{Bu}$ değerler ölçeğin iyi uyum gösterdiğine işaret etmektedir (Kline, 2015).

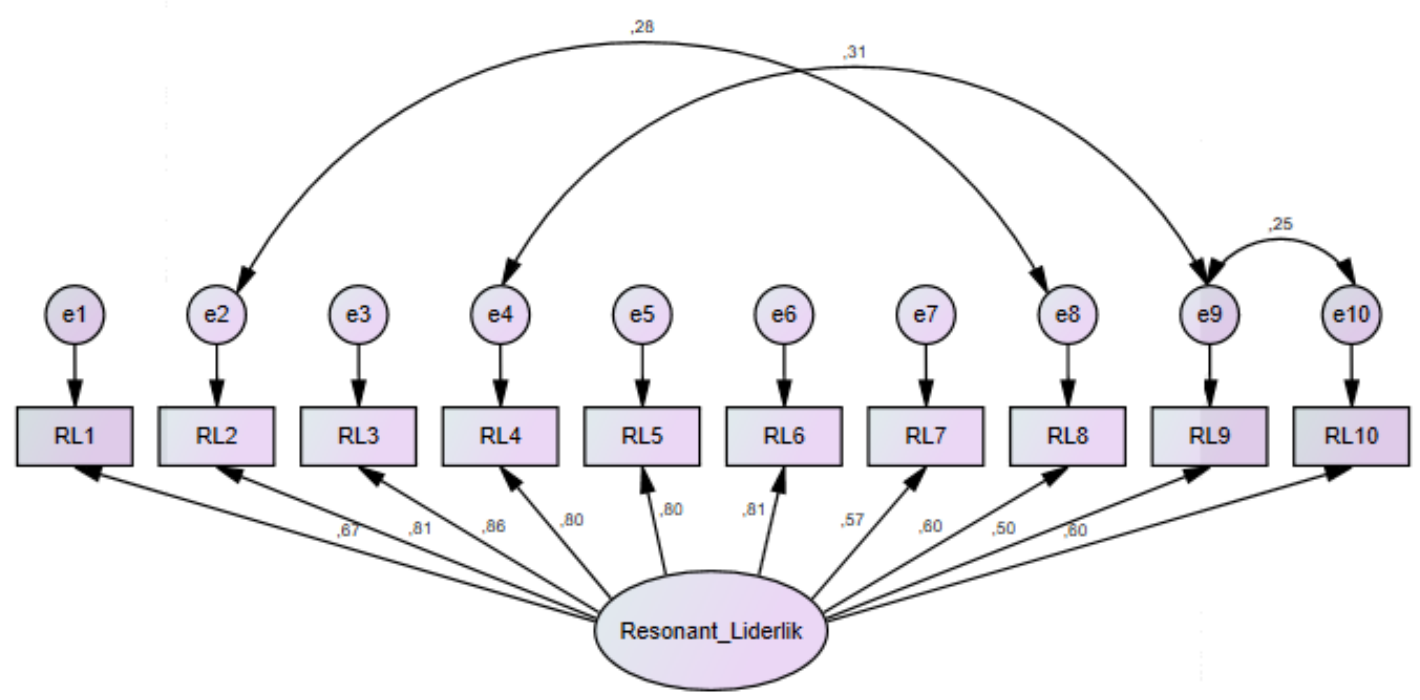

Şekil 1. 10 ifadeli Resonant Liderlik Ölçeğinin Doğrulayıcı Faktör Analiz Diyagramı 


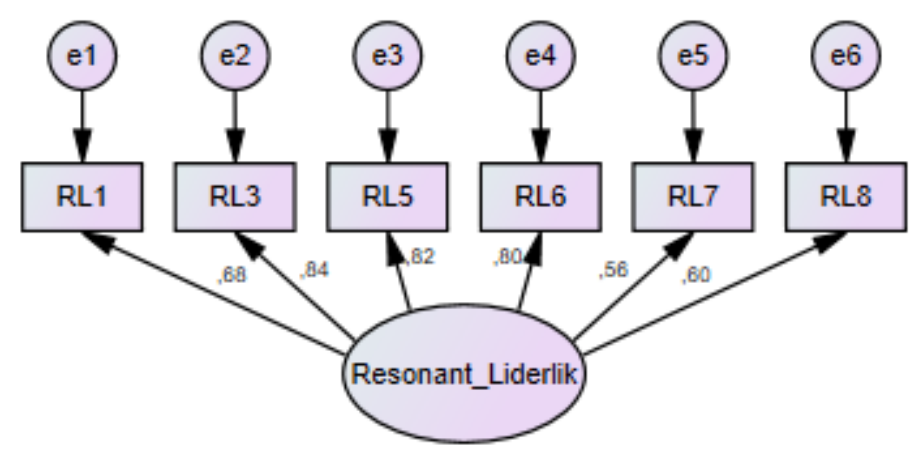

Şekil 2. 6 ifadeli Resonant Liderlik Ölçeğinin Doğrulayıcı Faktör Analiz Diyagramı

\subsection{Güvenirlik Çalışmaları}

Güvenirlik, ölçme aracıyla aynı koşullarda tekrarlanan ölçümlerde elde edilen ölçüm değerlerinin kararlılığını gösterir (Sürücü ve Maslakçı, 2020: 2695). Diğer bir ifadeyle güvenirlik ölçüm aracının farklı zamanlarda uygulandığında, benzer sonuçlar verme yeteneğidir. Ampirik araştırmalarda kullanılan ölçeklerin güvenilirliğini tespit etmek için literatürde farklı yöntemler kullanılmaktadır. Bunlar arasında en çok uygulanan yöntemler iç tutarlılık değerlerinin tespiti ve test-tekrar testinin uygulanmasıdır (Sürücü ve Maslakçı, 2020: 2707). Bu nedenle araştırmada öncelikle uyarlama ve çeviri çalışması yapılan resonant liderlik ölçeğinin iç tutarlılı̆̆ı tespit edilmiştir. İç tutarlılığının tespit edilmesine yönelik olarak Cronbach alfa iç tutarlılık katsayısı ve bileşik güvenilirlik değerleri hesaplanmıştır. 10 ifadeli ölçeğin Cronbach alfa değeri 0,909 ve birleşik güvenirlik değeri ise 0,912'dir. Altı ifadeli kısa versiyonun ise Cronbach alfa değeri 0,864 ve birleşik güvenirlik değeri 0,867 olarak ölçülmüştür. $\mathrm{Bu}$ değerler literatürde yaygın olarak kabul edilen 0.7 alt eşiğinin üzerindedir (Hair, Black, Babin ve Anderson, 2010; Sürücü ve Maslakçı, 2020). Elde edilen bulgular uyarlama ve çeviri çalışması yapılan resonant liderlik ölçeğinin iç tutarlılığının yüksek olduğunu göstermektedir.

Test-tekrar test güvenilirliği, ölçüm aracının farklı zamanlar içerisinde elde edilen sonuçların tutarlığını ifade eder (Sürücü ve Maslakçı, 2020: 2707). Test tekrar test uygulanarak ölçeğin tekrarlanabilirliği ve tekrarlarındaki kararlılığı tespit edilebilir. Bu maksatla uyarlama ve çeviri çalışması yapılan ölçeğin zamana karşı tutarlılığını tespit etmek için iki hafta ara ile aynı örneklem grubuna anket uygulaması yapılmıştır ( $\mathrm{n}=58)$. İki anket verisi arasında korelasyon $r=0,875$ (10 ifadeli ölçek) ve $r=0,921$ (6 ifadeli kısa versiyon) olarak ölçülmüştür. Whiston (2012) iki anket verisi arasında korelasyonun 0,80 ve üzerinde olması durumunda ölçeğin test tekrar test güvenirliliğini sağladığını belirtmektedir. Araştırmada elde edilen değerler ölçeğin test tekrar test güvenirliğinin olduğunu göstermektedir. Çalışmada ayrıca iki anket verisi arasında anlamlı bir farklılık olup 
olmadığını tespit etmek için t-testi yapılmıştır. T testi sonuçları iki anket verisi arasında anlamlı bir farklılığın bulunmadığını göstermektedir $(\mathrm{t}=3.249, \mathrm{t}=2.781$ ve $\mathrm{p}>0.05)$.

Yapılan tüm güvenirlik analiz sonuçları, uyarlama ve çevirisi yapılan resonant liderlik ölçeğinin güvenilir olduğunu göstermektedir.

\section{Sonuç}

Literatür, geliştirilen ve uygulanan ölçeklerin araştırmanın yapıldığı evrene ve kültüre göre değiştiğini belirtmektedir. $\mathrm{Bu}$ nedenle, farklı kültürde geliştirilmiş olan ölçeklerin araştırmanın yapıldığı dile uyarlanması, geçerlilik ve güvenirliliği test edilmiş olması, araştırmanın sağlıklı sonuçlar vermesi için önemlidir. Bu yaklaşımdan hareketle araştırmada Estabrooks vd. (2009) tarafından “Alberta Bağlam Aracının” bir alt ölçeği olarak geliştirilen resonant liderlik ölçeğinin Türkçeye çeviri ve uyarlaması yapılarak geçerlik ve güvenirliği test edilmiştir. Böylelikle yapılan bu çalışma Türkçe yazınında resonant liderliğe yönelik nicel araştırma yapılabilmesine olanak sağlamaktadır.

Araştırmanın amaçları doğrultusunda öncelikle ölçek geliştirme çalışması yapan yazarlardan olan Greta G. Cummings (gretac@ualberta.ca) ile iletişime geçilerek ölçeğin çeviri ve uyarlamasının yapılabilmesi için müsaade alınmıştır. Daha sonrasında ölçeğin çeviri işlemi araştırmacılarında içinde bulunduğu 6 akademisyen ve bir uzman tarafindan yapılmıştır. Çeviri işleminde Brislin vd. (1973) tarafından önerilen 5 aşamalı metot izlenmiştir. Ölçekte yer alan ifadelerin anlaşılır olup olmadığının tespit edilmesi maksadıyla 42 kişilik örnek gruba anket uygulanmış ve anlaşılırlığında tereddüt yaşanan ifadelerin olmadığı tespit edilmiştir. Ölçeğin geçerliğinin tespit edilmesi için öncelikle dilsel geçerlilik kontrol edilmiştir. Bu maksatla İngilizce ve Türkçe dillerine hâkim 47 kişilik örneklem grubuna ölçeğin orijinal formu ve Türkçe formu iki hafta ile uygulanmıştır. Elde edilen veriler iki form arasında yüksek korelasyon olduğunu ve formlar arasında anlamlı bir farklılığın bulunmadığını göstermiştir ( $r=0,901$ ve $r=0,884, \mathrm{p}<0,05)$. Benzeşim geçerliğinin tespit edilmesine yönelik olarak uyarlama çalışması yapılan ölçeğin uzun ve kısa versiyonlarının AVE ve birleşik güvenirlik $(\mathrm{Cr})$ değerleri hesaplanmıştır (uzun versiyon; $\mathrm{AVE}=0,507, \mathrm{Cr}=$ 0,912, kısa versiyon; $\mathrm{AVE}=0,526, \mathrm{Cr}=0,867)$. AVE değerlerinin $\mathrm{Cr}$ değerinden küçük olmas1 ve AVE değerinin 0,5 değerinden büyük olması çeviri ve uyarlama çalışması yapılan ölçeğin benzeşim geçerliğinin olduğunu göstermektedir. Ölçeğin yapı geçerliliğinin tespit edilmesine yönelik olarak yapılan keşfedici ve doğrulayıcı faktör analiz sonuçları ölçeğin tek faktörlü bir yap1 oluşturduğunu ve oluşturulan yapının iyi uyum indekslerine sahip olduğunu göstermektedir (uzun versiyon; $\chi 2=67,904, \mathrm{df}=32, \chi 2 / \mathrm{df}=2,122, \mathrm{GFI}=0,954, \mathrm{NFI}=0,957$, 
$\mathrm{TLI}=0,967, \mathrm{CFI}=0,977, \mathrm{RMSEA}=0,063, \mathrm{k} 1 \mathrm{sa}$ versiyon; $\chi 2=17,529, \mathrm{df}=9, \chi 2 / \mathrm{df}=1,948$, $\mathrm{GFI}=0,979, \mathrm{NFI}=0,977, \mathrm{TLI}=0,981, \mathrm{CFI}=0,988, \mathrm{RMSEA}=0,058)$.

Resonant liderlik ölçeğinin geçerliğinin tespit edilmesinde son güvenirliğinin tespitine yönelik analizler yapılmıştır. Bu maksatla ölçeğin Cronbach alfa iç tutarlılık katsayısı ve bileşik güvenilirlik değeri hesaplanmış ve zama karşı tutarlı sonuçlar verip vermediğinin tespit edilmesi maksadıyla test-tekrar test yapılmıştır. Analiz sonuçları ölçeğin güçlü bir iç tutarlılığın olduğunu göstermektedir (uzun versiyon; Cronbach alfa $=0,909, \mathrm{Cr}=0,912, \mathrm{k} 1 \mathrm{sa}$ versiyon; Cronbach alfa $=$ değeri $0,864, \mathrm{Cr}=0,867)$. Zamana karşı yapılan test- tekrar test sonuçları ise ölçeğin zaman karşı tutarlı sonuçlar verdiğini göstermektedir $(r=0,875, r=$ 0,921).

Sonuç olarak elde edilen bulgular, uyarlama ve çeviri çalışması yapılan resonant liderlik ölçeğin geçerli ve güvenilir bir ölçme aracı olduğunu göstermektedir. Araştırmanın resonant liderliğe yönelik anlayışımızı zenginleştirmenin yanı sıra ileride yapılacak olan çalışmalara kaynak teşkil edeceği değerlendirilmektedir. 


\section{KAYNAKÇA}

Anastasi, Anne ve Susana Urbina. 1997. Psychological Testing. New York: Prentice Hall/Pearson Education.

Brislin, Richard, LonnerWalter J. ve Thorndike Robert. 1973. Cross-Cultural Research Methods, New York: John Wiley/SonsPub.

Cronbach, Lee J. 1951. "Coefficient Alpha and The Internal Structure of Tests." Psychometrika 16(3): $297-334$.

Cummings, Greta. 2006. "Hospital Restructuring and Nursing Leadership - A Journey from Research Question to Research Program." Nursing Administration Quarterly 30: 321-329.

Cummings, Greta, Karin Olson, Leslie Hayduk, Debra Bakker, Margaret Fitch, Esther Green, Lorna Butler ve Michael Conlon. 2008. "The Relationship Between Nursing Leadership and Nurses Job Satisfaction in Canadian Oncology Work Environments.” Journal of Nursing Management 16: 508-518.

Cummings, Greta. 2004. "Investing Relational Energy: The Hallmark of Resonant Leadership." Canadian Journal of Nursing Leadership 17(4): 76-87.

Estabrooks, Carole A., Janet E. Squires, Greta G. Cummings, Judy M. Birdsell ve Peter G. Norton. 2009. "Development and Assessment of the Alberta Context Tool." BMC Health Services Research 9(1): 112.

Bawafaa, Eunice. 2014. The Influence of Resonant Leadership and Structural Empowerment on the Job Satisfaction of Registered Nurses, Yüksek lisans Tezi, The University of Western Ontario, London, Ontario, Canada.

Fornell, Claes ve David F. Larcker. 1981. "Evaluating Structural Equation Models with Unobservable Variables and Measurement Error." Journal of Marketing Research 18(1): 39-50.

Freshman, Brenda ve Louis Rubino. 2002. "Emotional Intelligence: A Core Competency for Health Care Administrators." The Health Care Manager 20(4): 1-9.

Goleman, Daniel. 1998. "The emotionally competent leader." In The Healthcare Forum Journal 41(2): 36-38.

Goleman, Daniel, Richard Boyatzis ve Annie Mckee. 2002. The New Leaders: Transforming the Art of Leadership into the Science of Results. London, UK: Little, Brown.

Goleman, Daniel, Richard E. Boyatzis, Annie McKee, and Sydney Finkelstein. 2017. Harvard Business Review Everyday Emotional Intelligence: Big Ideas and Practical Advice on How to Be Human at Work. Harvard Business Press.

Gürbüz, Sait ve Faruk Şahin. 2016. Sosyal Bilimlerde Araştırma Yöntemleri. Ankara: Seçkin Yayıncılık.

Hair, Joseph, William C. Black, Barry J. Babin ve Rolph E. Anderson. 2010. Multivariate Data Analysis: A Global Perspective (7th ed.). New Jersey: Pearson Education, Upper Saddle River.

Hambleton, Ronald ve John Bollwark. 1991. "Adapting Tests for Use in Different Cultures: Technical Issues and Methods." Bulletin of the International Testing Commission 18: 3-32.

Hassan, Masood ve Azeem Qureshi. 2019. "Resonant Leadership at Workplace: How Emotional Intelligence Impacts Employees'attitudes-A Cross-Sectional Study.” Pakistan Business Review (21)2: 237-251.

Klein, Robert R. 2009. "A Review of Becoming a Resonant Leader (McKee, Boyatzis, and Johnston): Contextualizing The Place Of Emotional Intelligence Skills with Respect to Team Leadership and Group Dynamics.” Organization Management Journal 6(1): 58-63.

Kline, Rex B. 2015. Principles and Practice of Structural Equation Modeling. Guilford Publications.

Kushwaha, Anurag. 2019. Resonant Leadership and It's Impact on Psychological Empowerment in Automotive Organizations. In International Conference on Advances in Engineering Science Management \& Technology (ICAESMT)-2019, Uttaranchal University, Dehradun, India.

Laschinger, Heather, Spence Carol Wong, Greta G. Cummings ve Ashley L. Grau. 2014. "Resonant Leadership and Workplace Empowerment: The Value of Positive Organizational Cultures in Reducing Workplace Incivility." Nursing Economics 32(1): 5-15.

McKee, Annie ve Dick Massimilian. 2006. "Resonant Leadership: A New Kind of Leadership for The Digital Age." Journal of Business Strategy 27(5): 45-49.

McKee, Annie, Richard E. Boyatzis, Fran Johnston ve Frances Johnston. 2008. Becoming a Resonant Leader. Boston, MA: Harvard Business Press.

Pirola-Merlo, Andrew, Charmine Härtel, Leon Mann ve Giles Hirst. 2002. "How Leaders Influence The Impact of Affective Events on Team Climate and Performance in R\&D Teams." The Leadership Quarterly 13(5): 561-581.

Ramírez Molina, Ramineth Joselin, Marisol del Valle Marcano, Reynier Israel Ramírez Molina, Nelson David Lay Raby ve Belina Annery Herrera Tapias. 2019. "Relationship Between Social Intelligence and Resonant Leadership in Public Health Institutions." Opción 90:1223-1249.

Reivich, Karen ve Andrew Shatté. 2002. The Resilience Factor: 7 Essential Skills for Overcoming Life's Inevitable Obstacles. New York: Broadway Books.

Squires, Mae, Heather K. Tourangeau, Spence Laschinger ve Diane Doran. 2010. "The Link Between Leadership and Safety Outcomes in Hospitals." Journal of Nursing Management 18(8): 914-925. 
Sürücü, Lütfi ve Ahmet Maslakçı. 2020. "Validity and Reliability in Quantitative Research.” BMIJ 8(3): 26942726.

Tabachnick, Barbara G., Linda S. Fidell ve Jodie B. Ullman. 2007. Using Multivariate Statistics. Boston, MA: Pearson.

Turk, Ellen ve Zora M. Wolfe. 2019. "Principal's Perceived Relationship Between Emotional Intelligence, Resilience, and Resonant Leadership throughout Their Career." International Journal of Educational Leadership Preparation 14(1): 147-169.

Wagner, Joan IJ, Sharon Warren, Greta Cummings, Donna L. Smith ve Joanne K. Olson. 2013. "Resonant Leadership, Workplace Empowerment, and "Spirit at Work": Impact on RN Job Satisfaction and Organizational Commitment." Canadian Journal of Nursing Research Archive 45(4): 108-128.

Whiston, Susan C. 2012. Principles and Applications of Assessment in Counseling. Cengage Learning. 